\title{
Scientific Preparations of Archaeological Ceramics Status, Value and Long Term Future
}

\author{
Patrick Quinn \\ Institute of Archaeology, University College London, 31-34 Gordon Square, London, WC1H 0PY, United Kingdom. \\ patrick.quinn@ucl.ac.uk
}

\begin{abstract}
Thin sections, resin blocks, pressed pellets, fused beads, milled powders, solutions and digested residues are several key sample formats used in the invasive scientific analysis of ancient ceramics. They are crucial tools that enable researchers to characterise the mineralogical, geochemical, molecular and microstructural composition of pottery and other ceramic artefacts, in order to interpret their raw materials, manufacturing technology, production locations and functions. Despite the importance of such preparations, key issues about their status, such as whether they are still artefacts or not, who owns them and where they should reside after analysis, are rarely addressed in the archaeological or archaeometric literature. These questions have implications for the long-term future of thin sections, resin blocks and other sample formats, as well as their accessibility for future research. The present paper highlights the above problem and assess the roles, perspectives and needs of ceramic analysts, field archaeologists, commercial units, curators, policy makers, professional bodies, special interest groups and funding agencies. Finally, guidelines are put forward that can be taken into account when deciding on the value, research potential of scientific specimens of archaeological ceramics, as well as strategies for their curation.
\end{abstract}

\section{Keywords}

Ceramic compositional analysis; Scientific preparations; Reference library; Curation; Archive

\section{Introduction}

Archaeological ceramic analysis applies methods from the earth sciences, physics and chemistry to characterise the inorganic and organic composition of pottery and other types of ceramics. This is used to determine the production location of artefacts, reconstruct aspects of their manufacturing technology, date them and interpret the uses that they served in the past. Such data provides important evidence for the activities of ancient societies and can contribute to themes such as trade and exchange, migration, organisation of craft production, tradition and transmission of skills. Key approaches include thin section petrography, instrumental geochemistry, scanning electron microscopy, $\mathrm{X}$-ray diffraction and organic residue analysis. In most cases it is necessary to sub-sample the studied ceramic artefact(s) and prepare them in a specific format for analysis. These include thin sections, polished resin blocks, mounted specimens, milled powders, pressed pellets, fused glass beads, digested solutions and extracted residues (Figure 1). Samples are analysed via scientific apparatus and compositional and/or microstructural data of various types is collected in order to answer archaeological questions and test hypotheses posed by other evidence.

Scientific ceramic analysis has a long history and is regularly applied to academic research projects and commercial archaeological investigations in many parts of the world. In most cases an assemblage of several carefully selected ceramic artefacts is subjected to analysis, often via several complimentary methods, such as thin section petrography and instrumental geochemistry. This results in the production of thousands of scientific specimens by numerous laboratories each year, which are used to collect a vast amount of data. The fate of these samples, once analysis and data collection has taken place, varies considerably. Many are retained by the analyst in their personal collections or 
become part of laboratory reference libraries. Some specimens are returned to the museum, repository or commercial unit at which the parent artefact is housed. Others may be discarded or simply left behind when a project ends or the researcher moves institution, retires or dies.

This variation in practice is not always helpful in terms of access to material for repeat analyses, and can have a detrimental effect on the compatibility of data. It can also impact on the preservation and longevity of scientific sample collections, as well as the conservation of their unique and finite parent artefacts. Opinions differ greatly on the true value of scientific preparations of archaeological ceramics post-analysis, as well the question of what exactly what it is that they represent. These are strongly influenced by the perspectives and needs of the main parties involved in ceramic analyses, including ceramic analysts, field archaeologists, commercial units, curators, government agencies, special interest groups and funding bodies. Occasional disputes over the custody of scientific samples underline a lack of agreement on this topic. Practices vary geographically due to different national and regional legislation, or lack thereof, and can also differ depending on the archaeological date, excavation location and the perceived importance of the specific ceramic parent object from which a sample was made. In addition, the format of a particular scientific preparation and its method of analysis are key factors in deciding what happens to it after analysis.

Formal guidelines on the treatment of studied specimens are sorely lacking within the extensive body of literature that exists on the fields of archaeological ceramic analysis, museum curation and heritage law. Despite the importance of this topic, it is rarely discussed on more than a case by case basis. Though a one-size-fits-all solution is not appropriate given the diversity of ceramic research projects undertaken worldwide, detailed consideration of the issue is very much overdue. By reviewing the range of perspectives on the status, value and custody of scientific preparations of archaeological ceramics, this paper intends to make a much needed start. This is achieved by reviewing the main sample formats in terms of what they represent, how they are analysed and the ways in which they are normally treated post-analysis. A detailed consideration is then made of the roles, perspectives and needs of ceramic analysts, archaeologists, commercial units, curators, policy makers, professional bodies and funding agencies in relation to scientific preparations of ancient ceramics. Finally, a set of considerations are proposed that might be taken into account when deciding on the fate of such samples.

This paper focuses on the scientific analysis of ceramics only, however many of the issues that are discussed are applicable to other types of artefacts including metals, glass, stone and organic materials. Ceramics are analysed scientifically in a wide variety of formats, many of which are also used for the study of these other material remains. The paper has drawn upon the author's experience analysing archaeological ceramics from several parts of the world, both as part of academic research and consultancy. It has also benefitted from discussions with colleagues from the field of ceramic analysis, as well as communication with field archaeologists, curators, commercial units and funding agencies. The paper has mainly consulted literature published in the English language and research undertaken in the UK, however, examples and opinions have been drawn from elsewhere where these were available. While the paper is unlikely to represent the full spectrum of opinions and practices surrounding scientific preparations of ceramics, it is hoped that by explicitly focussing on the topics of their status, value, custody and curation, that the various parties involved have a better appreciation of each others' needs and points of view. This may help inform future decisions on this important and sometimes sensitive matter, or at least stimulate further informed debate.

\section{Scientific Sample Formats}

Archaeological ceramics are analysed scientifically via a wide range of approaches and apparatus (see Hunt 2016 and chapters therein). Most of these require the sample to be prepared in a specific format in order for data to be collected. Common types include thin sections, polished resin blocks, 
mounted specimens, milled powders, pressed pellets, fused glass beads, inorganic solutions and extracted residues (Figure 1). It is worth considering the nature of these various preparations, the ways in which they are studied, the data that is collected and their requirements in terms of curation and re-analysis.

Thin sections are slices of an artefact that are made by cutting off a small chip, attaching it to a glass microscope slide and grinding this down to a thickness of $0.03 \mathrm{~mm}$ (Figure 1A). These are studied under a polarising light microscope used for the analysis of geological thin sections. Thin sections typically require the removal of one or more grams of a sherd and the off-cut that remains after preparation is either encased within or covered by resin so is not always returned. If stored in purposemade boxes and handled carefully, these delicate glass microscope slides represent a permanent record of the composition of an artefact that can be restudied repeatedly and in several different ways (Rice 1987, p. 373; Quinn 2013, p. 33).

Scanning electron microscopy (SEM) of ceramics can be performed on small fragments of sherds, mounted on a metal stub and coated with either gold or carbon to make it conductive (Figure 1B). Samples for such analyses vary in size but can be small $(<1 \mathrm{~g})$ and are typically prized or cut off their parent artefact with pliers or a diamond saw. Setting specimens within a block of resin and polishing their exposed surface with fine diamond compounds (Figure 1C), provides an opportunity to undertake microanalysis of inclusions, pottery surface finishes and other features, using the SEM in backscattered electron mode or with an energy dispersive detector (SEM-EDS) or with an electron microprobe (EMPA). Polished blocks and SEM mounts can be kept for many years for the purpose of reanalysis, if stored in a dry, dust free environment. Their surfaces can however tarnish over time and may need re-polishing and re-coating with specialist laboratory equipment.

Bulk geochemical characterisation of ceramics produces quantitative data on the abundance of a range of elements or isotopes of a single element present in the sample. It can be undertaken using several types of apparatus, including instrumental neutron activation analysis (INAA), x-ray fluorescence spectroscopy (XRF) and inductively-coupled plasma mass spectrometry (ICP-MS). Each of these has their own methods of sample preparation, however a small amount (c. 1-5 g) of powdered, homogenised sample (Figure 1D) is required for all three approaches, which can be either removed from a sherd by drilling, or produced by grinding a small piece in an pestle and mortar or ball mill. This powder is then analysed directly in a nuclear reactor in the case of INAA, pressed into a pellet or fused with glass in a bead (Figure 1E, F) and bombarded with X-rays for XRF, or dissolved with strong acids and aspirated as a solution (Figure 1G) into an argon flame in the technique of ICP-MS. Reanalysis is possible for ceramic samples prepared for INAA and XRF, but ICP-MS solutions are ionised during analysis and not recoverable. Pellets and beads for XRF can be easily stored in a dry environment, however, powders analysed by INAA are rendered radioactive during the process and therefore need to be handled or disposed of with caution.

Several other techniques including mineralogical analysis via $\mathrm{X}$-ray diffraction (XRD) and molecular characterisation via fourier transform infrared spectroscopy (FT-IR) make use of powdered samples 
(Figure 1D). In both cases, the powders and disks can be re-analysed if necessary, but should be

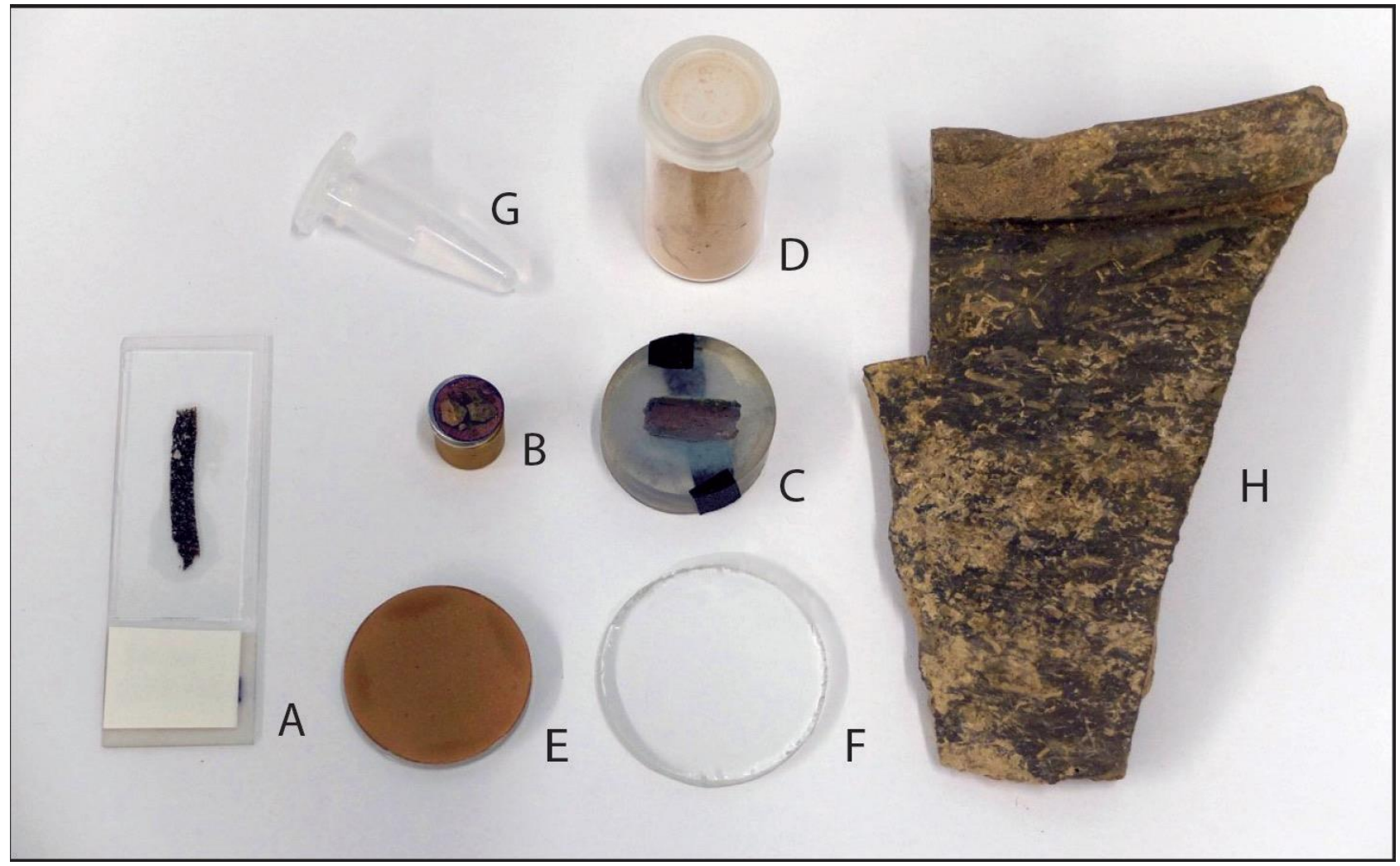

stored in a dry environment when not being used.

Figure 1. Scientific sample formats used for the compositional analysis of archaeological ceramics. Thin section (A), SEM mount (B), polished block (C), milled powder for INAA, XRD, FT-IR (D), XRF pressed pellet (E) and fused bead (F), digested solution for ICP-MS/extracted residue for GC-MS (G). Archaeological ceramic specimen with visible evidence of invasive sampling for compositional analysis $(\mathrm{H})$.

The analysis of organic residues trapped within archaeological ceramics via gas chromatography mass-spectrometry (GC-MS) requires the destruction of a small portion of sherds $(\mathrm{c}$. $1 \mathrm{~g})$. This is powdered and the organic molecules are dissolved into solution using solvents. As with ICP-MS, the solution is subsumed during analysis and cannot therefore be restudied. Treated powders may contain more organic residue, so are commonly retained for additional sampling or for use in other inorganic analyses.

The 'invasive' methods of ceramic analysis outlined above all require the destruction or modification of the studied samples(s) in some way. This has implications as to whether the resulting preparations can still be considered as archaeological artefacts. Extreme modification takes place as part of solution ICP-MS and XRF analysis via glass beads, in that the material is broken down to its basic elemental components and reconstituted as part of another substance. Residue analysis involves the removal of the organic component of the ceramic sample from its inorganic constituents. The scientific samples resulting from these three methods of preparation therefore bear no resemblance to their parent object and do not preserve any of its original macroscopic or microscopic characteristics. In this respect they are no longer artefacts, but rather the highly deconstructed remains of the ceramic sherd(s) under study.

Powdered samples for geochemical analysis via INAA and pressed pellet XRF are composed of very fine (c. 50 micron) particles of a ground up ceramic. Though some of these will be fragments of mineral inclusions from the original sherd, they are extremely small and highly disaggregated, or in 
the case of pressed pellets, reconstituted in another order. In this respect, it is difficult to argue that such preparations represent artefacts, as they do not reflect their parent sample in terms of shape or microstructure.

In the case of polished blocks and thin sections, the prepared sample is far less altered and its main component parts, namely the clay matrix, inclusions and voids, remain intact in the order that they existed in the original artefact (Orton and Hughes 2013, p. 289). Though both methods of preparation involve the cutting and polishing of the sample and its bonding to or encasing within other material, it may be argued that the resulting specimens are still small pieces of an artefact. They often retain the shape and size of the sherd, albeit in two dimensions, as well as its colour, and in some cases, decorative coatings such as slip, paint and glaze. Ceramic chips mounted on SEM stubs represent the least altered of the scientific sample formats outlined above. They are small three-dimensional fragments of their parent artefact that have been glued to a stub and coated with gold or carbon.

Some of the common sample types for invasive ceramic analysis can be easily stored and survive for many years. These include thin sections and XRF beads, which are made of glass and do not degrade under room conditions. Polished blocks, SEM mounts and pressed pellets are less stable and require a desiccator to keep them in good condition, as well as occasional re-polishing, re-coating or repressing prior to analysis. Though milled powders can be kept safe in airtight vials, those that have been analysed by INAA are radioactive and need to be stored or discarded very carefully. Dissolved solutions containing the inorganic or organic remains of ceramics can be stored in sealed bottles for short periods of time, but do not preserve well and may eventually give different results if reanalysed.

Appropriate equipment is required to re-analyse specimens prepared for the scientific approaches discussed above. These range from the fairly simple, such as a polarising light microscope for examining thin sections, to the extremely specialist, in the case of a nuclear reactor used for INAA. Only thin section petrography can be performed without the need to take the specimens to a specialist laboratory. Small, portable and affordable geological microscopes (Quinn 2013, p. 3; Goren 2014) can be used to undertake petrographic analysis of prepared thin sections in most locations.

\section{Roles, Needs and Perspectives of Parties Involved}

The scientific study of archaeological ceramics is a process that involves several parties, in addition to the specialist who undertakes the actual data collection and interpretation. These include archaeologists in charge of field projects that incorporate analyses of excavated ceramics, commercial units commissioning specialist post-ex investigations of their finds, and developers funding archaeological excavation. Research projects on ceramic analysis initiated by academic experts often target material housed in museum collections. Access to and sampling of these involves negotiation with curators, who are responsible for artefact storage and curation. Other less directly involved parties include national and local government, funding agencies, professional bodies and special interest groups. The roles, needs and perspectives of these various parties, with respect to scientific ceramic analysis and the treatment of the studied samples, are explored in turn below.

\section{Ceramic Analysts}

Ceramic analysts, defined here as individuals that undertake petrographic, geochemical, microstructural or spectroscopic studies of pottery or other ceramic materials, are arguably the most important party in any scientific analyses of artefacts. This is because such studies cannot take place without their participation, whereas the other personnel may or may not be involved in the process. The majority of scientific specialists working on ceramics are affiliated with universities and carry out analysis as part of academic research projects, often externally funded, that are based on artefacts housed elsewhere. Museum scientists may also analyse ceramics, typically material from the collections of 
their own institution. A final, less common type of analyst is the professional specialist, who may work for a commercial outfit, or more commonly, as an independent sub-contractor, on developerfunded projects.

Analysts have the technical skills and know-how to perform scientific analyses as well as access to the necessary equipment. They usually have a good understanding of sample preparation, and in some cases, will have carried this out themselves. They are familiar with the storage and safe keeping of scientific preparations of ceramics and are the most likely party to wish to reanalyse these at a later date. For the above reasons, ceramic analysts have a close relationship with the thin sections, polished blocks and other specimens that they analyse. This results in a sense of ownership and even a fond attachment, especially when it comes to material from personal research projects such as doctoral theses. It is therefore common for analysts to wish to keep their samples after they have been analysed, or to expect to be able to. In the absence of any prior arrangement or subsequent request from another of the parties, this is often what happens.

There are several benefits to scientific samples remaining with the analyst. By building up reference library, for example a database of thin sections of ceramics of a specific region, period, style or composition (Quinn 2013, p. 14, 33, 37; Cordell et al. 2017), or a library of powdered samples for geochemical characterisation (Boulanger and Stoner 2013), it is possible to greatly bolster future provenance or technological interpretations of similar material. This is particularly relevant to thin section petrography, where access to the original slides is far more desirable than petrographic descriptions or photomicrographs, and the same samples can be re-studied in numerous ways to yield different types of data. In this respect, reference collections are a crucial part of this discipline.

Academic ceramic analysts commonly pass on their skills via university courses and training programs, thus nurturing the next generation of practitioners in their field. Previously analysed scientific samples play a vital role in teaching, in the form of examples of specific compositions and microscopic features that can be examined by students, used for lecture presentations and included in textbooks (e.g. Reedy 2008; Ingham 2010; Quinn 2013). This is particularly true of ceramic thin sections, which can be reexamined and compared quickly and conveniently, as well as being handed out to groups of students to examine in classes. Without reference collections for comparative purposes and as pedagogical material, the research and teaching capability of ceramic petrographers is somewhat restricted. A similar case can perhaps be made for SEM mounts and polished blocks of ceramics. Pellets, beads and other samples for geochemical characterisation are less frequently re-analysed to yield new data or used for teaching, though they may be used for quality control.

Given the value of scientific preparations to ceramic analysts, it is surprising to find that the subject of their post-analysis treatment is given very little attention in relevant literature (Rice 1987; Peterson 2001; Orton and Hughes 2013; Quinn 2013) or not mentioned at all (Tite 1999; Henderson 2000; Pollard et al. 2007; Reedy 2008; Albero Santacreu 2014; Hunt 2016). Discussion has instead focussed on the archiving and accessibility of scientific data collected during analysis (e.g. Quinn et al. 2011; Hein and Kilikoglou 2012). In reviewing the process of scientific ceramic analysis, Rice (1987, p. 372 ) asks whether samples or their remnants should be returned after analysis, but does not provide an answer to this question, nor any further discussion of the topic. Orton and Hughes (2013, p. 289) state that the question of the long-term curation of prepared samples is "a problem" and similarly Quinn (2013, p. 33) points out that "ceramic thin sections are not normally curated in the same manner as the artefacts from which they were made" and "this makes it difficult to gain access to comparative collections". The most explicit reference to this topic is that of Peterson (2001, p. 8), who suggests that "completed thin sections and fragments can be archived in a petrographic library or other facility to aid future research". 
Ceramic analysts appear to have either shied away from this important topic or simply not given it significant consideration. In many cases, scientific samples are automatically retained by the analyst without any objection from another party. In others, they may be routinely returned to their source. In certain countries that have strict export rules on artefacts (e.g. Greece) scientific preparations themselves are not covered by legislation, so may be transported and retained by analysts. The presence of such a loophole means that it is not advisable to broach the subject of their ownership and custody.

A rare attempt to flag existence and location of scientific preparations in order to improve access to them was the United Kingdom Thin Section Database (UKTS), commissioned by Historic England in the 1990s (Morris and Woodward, 2003; Vince 2001, 2005). This survey of ceramic thin section collections housed at UK institutions revealed some 20,000 individual samples of prehistoric to postmedieval date, in 48 separate locations. The process of compiling the database highlighted the requirement for a minimum standard of information to be included in petrographic reports. Surprisingly, the need to provide a clear indication of the whereabouts of thin sections used analytical projects was not included in the guidelines that were proposed (Morris and Woodward 2003, p. 299; Vince 2005, p. 224). The project also failed to tackle the question of how the 20,000 thin sections ended up in so many different locations, nor what might have happened to the specimens that were not detected by the survey.

A relatively small number of laboratories have a clear policy of retaining the scientific samples that they produce and analyse. These include the Archaeometry Laboratory of the University of Missouri Research Reactor (MURR), which undertakes geochemical analysis of pottery and other materials for academic projects (Boulanger and Stoner 2013) and ceramic consultancy at the Institute of Archaeology, University College London (Quinn 2017a, b). By requesting that prepared samples are retained, such laboratories ensure that this material has a safe home post-analysis and can be accessed by other parties if necessary.

A key question is what happens to sample collections held by analysts when they change institutions, retire or pass away. It is not uncommon for academic ceramic researchers to take their research and teaching collections with them when moving jobs. Many such samples are not registered with their institution, so can be transferred along with books, papers and other personal effects. This situation can make it difficult to establish the whereabouts of thin sections and other scientific samples from a particular research project and to gain access to them. Stricter controls usually exist when the analyst is based at museum, particularly if the specimens were prepared from artefacts housed in the institute's own collections. It is hoped that upon retirement or death, the collections of ceramic researchers are retained by their institution, kept safe and made accessible for comparative purposes by other staff members and external researchers. However, in cases where no interest and/or expertise in ceramic analysis remains after the said specialist departs, analysed scientific specimens may end up being neglected, inaccessible, forgotten about or even disposed of. In order to avoid this situation, institutions with a strong tradition of research in the field need to invest in space, equipment and manpower to house and manage the collections of their former staff. This is not always possible given constraints on resources and the low priority that is usually given to sorting out personal collections of departed colleagues.

The untimely death of key researchers can represent a challenge that needs to be tackled with haste in order to ensure that their samples are recovered and a plan is put in place. A example of good practice in the case of the late Alan Vince, an independent ceramic specialist who had amassed several thousand thin sections of mainly Medieval ceramics from sites in the UK and Europe (Lohman 2009). Alan died suddenly in 2009 leaving the future of his valuable collection uncertain. Luckily the Medieval Pottery Research Group (MPRG) stepped in to assess the extensive material that he left behind. They brought it to the attention of English Heritage, who funded its transferral to British Museum 
(Orton and Hughes 2013, p. 287-288). The collection can now be accessed and studied under the microscope by interested external researchers working on related material.

\section{Field Archaeologists and Commercial Units}

Academic archaeologists and commercial units conducting excavations that unearth ceramic specimens are a common users of scientific data recorded via methods such as thin section petrography, geochemistry and other approaches discussed in this paper. This is used to support interpretations of a range of past activities at ancient sites and may form a central role in addressing specific project goals. Compositional analysis is undertaken either through academic collaborations or the commissioning of external specialists. Some commercial units have in-house ceramic analysts (e.g. Desert Archaeology Inc., Tuscon, Arizona), though this is rarely the case these days.

Academic and commercial field projects can produce large numbers of scientific preparations, some of which are included in the project archive and transferred to an appropriate museum or repository (e.g. Pappas 2014; Lindeman 2016). While this makes sense in terms of completeness, it may be necessary to refer to certain samples at a later date, such as in future excavations and ceramic analyses from related sites. Obtaining or accessing these from a local museum in a foreign country can be problematic, so it is not uncommon for specimens to be retained by academic archaeologists or the analysts that they collaborate with. A certain sense of ownership may be attached to samples from archaeologists' personal fieldwork, especially if they have secured external funding with which to support such projects. Re-analysis of specimens is more likely to take place if the collaborating ceramic analyst(s) are based at the same institution and appropriate equipment is readily available. Otherwise samples may remain unused after their initial study and potentially inaccessible to other interested parties.

It may be necessary at a later date to re-study the specimens resulting from commercial ceramic analysis. However, not all commercial units have the space to curate artefacts, nor the time and money required to develop thin section or geochemical reference collections. Few firms have a petrographic microscope and even fewer are likely to possess analytical equipment for instrumental analysis via bulk geochemistry, scanning electron microscopy and other sophisticated techniques. For this reason ceramic analysts typically retain analysed scientific specimens from commercial projects. This can make it difficult for other researchers working on related material to gain access to thin sections or other samples from past commercial projects. The setting up of a central repository for specimens of a particular period or geographic is an idea that has been mooted in the UK, but may be difficult to implement given the large number of parties involved.

In terms of ownership, an argument could be made that commercial clients such as landowners and developers, have a claim to scientific preparations of ceramics (University of Wyoming Archaeological Repository 2017, p. 8), having payed for these and other post-excavation analyses. However, in most cases it the data and interpretation that they are paying for, not the physical products of this process.

\section{Curators and Collections Managers}

Archaeological ceramic finds are normally stored in museums, university collections or other repositories. The responsibility for looking after these, including dealing with requests for their study, falls to curators and collections managers. It is their duty to protect and preserve the unique, irreplaceable specimens in their collections so that they are available for future research, and in some cases for display. As invasive analysis is a direct threat to the preservation of such material, internal and external requests for thin sectioning, geochemistry and residue analysis usually involve detailed application process that includes a consideration of the value of a particular specimen, the benefits of the 
research, the suitability of the proposed method, its degree of impact on the object, the expertise of the analyst, and the future of any data that is collected. By weighing up the pros and cons of invasive analysis on a particular ceramic artefact, curators and collections managers make a decision as to whether to permit such research. In cases where permission is granted, the analyst usually travels to the museum in question to take subsamples for preparation and analysis back at their laboratory. Museum staff typically carry out or oversee the sampling process in order to ensure that material is taken in a sensitive manner, preserving important features such as decoration and artefact labelling.

Many larger museums and other repositories have strict regulations for the sampling of artefacts for invasive analysis, incorporating some or all of the considerations given above. However, it is surprisingly uncommon for such in-house rules to cover the custody, storage or long term access of scientific specimens produced as a result of ceramic analyses. A rare example is the guidelines of the Peabody Museum for Archaeology and Anthropology at Harvard University, which stipulates that "the researcher must agree to return to the Museum any unanalyzed/unprocessed remnant samples, including thin sections or sample blocks, within one year" (Peabody Museum 2016, p. 4). It is not clear whether this covers all prepared scientific samples or just those that have not been analysed. Another example is the British Museum's Scientific Study form EE1, which is also somewhat ambiguous in its requirement that "all mounted and residual samples shall be returned to the British Museum within one year unless otherwise agreed" (British Museum n.d., p. 2). Residual samples seem to be the leftovers/offcuts of any preparation process, but whether 'mounted' samples include all types of scientific preparations described above is not clear from the document.

From the point of view of curators and collections managers, several justifications can be made for the return of scientific specimens of archaeological ceramics after analysis. The most important of these seems to be a need to preserve the finite artefacts housed in their collections that have been subjected to invasive sampling. If analysed, thin sections, resin blocks, XRF pellets and the like end up in an analysts personal or institutional collections, or lost or discarded, then subsequent analysis of the same individual artefacts may require the destruction of additional material. It is not uncommon to find sherds with chunks cut out of them among museum collections (Figure 1H), without corresponding scientific preparations, nor any record of where these might reside. Early analytical studies were not always subject to the same level of restrictions on sampling as many are these days, resulting in the loss of significant portions of ceramic artefacts, as well as the thin sections and other preparations made from them. This lack of control has in some cases hampered subsequent re-analysis via modern techniques and perspectives, as very little is left of the original samples. By establishing a clear policy regarding the return of scientific preparations or information on their whereabouts, it may possible to prevent multiple invasive sampling of single artefacts, whilst still permitting future analyses.

A second, related justification for the retention of scientific specimens in museum collections is a desire to document and preserve the full biography of artefacts. In addition to the ceramic sherds themselves, this includes original labelling on the specimens, notes from their excavation as well as associated material such as visible residues that have become attached and perhaps surrounding sediment. This material provides additional information about the sherd or tells the story of its study, post excavation, including its perceived value and meaning to those who discovered it and examined it. As an example of this, a search within the catalogue of the Petrie Museum of Egyptian Archaeology, University College London, brought up a decorated pot (UC445i) from the excavations of Naqada Tomb \#1636 by Flinders Petrie (1921), which has an accompanying thin section (UC445ii) made by Henry Hodges, an early pioneer of ceramic petrography. The scientific analysis of artefacts is an important part of a sherds life history (Albero Santacreu 2014, p. 45, 48) and a case can therefore be made for the return of the resulting specimens and for incorporation into the archive. 
The application of scientific techniques to ancient ceramics hopefully adds value to them in terms of providing information on their origins, technology and embedded cultural meaning. In doing so, analytical studies have the potential to enliven collections that might otherwise be of less interest to museum visitors. In order to share the perspectives offered by scientific analysis, it is sometimes desirable to display the preparations themselves. This both tells the story of the object in the manner alluded to above, but also plays an educational role in demonstrating the means by which data is collected.

On a more fundamental level, many curators and collections managers seem to regard scientific preparations of archaeological ceramics as artefacts. The argument is that they are small fragments removed from their parent object and should therefore be treated in a similar manner to the sherds that they were prepared from. This is used in some cases to justify the return of thin sections, resin blocks and mounted specimens after analysis. These may be catalogued and assigned their own unique accession number, as is the case for thin sections prepared from ceramic specimens in the collections of Petrie Museum of Egyptian Archaeology mentioned above. For reasons discussed above, the case for milled powders, pellets, beads, solutions and extracted residues is more difficult to argue given that they bear little or no resemblance to their original ceramic specimens. Scientific preparations that were made as part of early, seminal compositional studies, such as the thin sections analysed by the likes of Ferdinand Fouque (1879) and Victorian petrographic pioneer Henry Clifton Sorby (Worley 1999) may take on antique quality and be considered artefacts in their own right, regardless of the $0.03 \mathrm{~mm}$ slice of ceramic that they contain.

Guidelines on the treatment of scientific preparations of artefacts are very rare in the extensive academic literature that exists on collections management and curation (e.g. Pearce 1990; Keene 2005; Matassa 2011; Sullivan and Childs 2017). A rare example is Brown (2003, p. 11), who highlights the "complete lack of recognition of the archive needs of scientific and environmental materials, including microscope slides" in the UK and considers the situation to be unacceptable. These concerns seems to have inspired recommendations published in the best practice documents of certain professional bodies (see below).

A case against the return of scientific specimens after analysis may be made on the grounds that museums often lack the scientific equipment and expertise to undertake further work on them or to enable others to do so. While museum staff may have a working knowledge the procedures involved in the more common types of archaeological ceramic analysis, few are sufficiently trained to carry it out. Thin sections are perhaps the most well known sample format and occasionally museums are equipped with a petrographic microscope to analyse these. However, it is safe to say that the apparatus and know-how needed to prepare and analyse resin mounted blocks, pressed pellets and extracted residues is not nearly as readily available. It is for this reason, according to Brown (2003, p. 11), that some museums prefer not to curate scientific specimens of artefacts.

\section{$\underline{\text { Policy Makers }}$}

Local and national governments recognise the historic environment as an important resource and have adopted various laws and policies for its study and management. In many countries these include rules on the export and analysis of artefacts including ceramics (for a detailed summary see Prott and O'Keef 1988), which are used to assess permit applications. With the exception of human remains, scientific preparations made from moveable cultural artefacts are rarely covered by such legal documents and orders, nor is the subject broached by academic discussion on archaeological law (e.g. Fitz Gibbon 2005; Forrest 2011; Blake 2015; Pickard 2016). This ambiguity can lead to quite different interpretations of the same legislation when it comes to thin sections, resin blocks and other samples. In certain countries in which it is illegal to export artefacts (e.g. Greece), prepared scientific specimens are sometimes removed by analysts for study in a foreign laboratory, without any challenge 
from curators, customs or other parties. While this has benefits for ceramic analysis, especially where equipment and expertise do not exist in the country of origin, it can also hamper future comparative study on related material, as the whereabouts of exported scientific specimens is not likely to be made public.

By including specific rules on scientific sample status, ownership and curation within archaeological law, policy makers have the potential to clarify the current murky situation and therefore standardise practice in their particular country or county/state/province. However, most legislation is typically too general and wide-ranging to prescribe such detailed regulations on ceramic compositional analysis, which is but small branch of a vast subject area. Furthermore, policy makers are not likely to be fully aware of the intricacies of the discipline, so run the risk of prescribing blanket policies that may hamper analysis.

\section{$\underline{\text { Professional Bodies and Special Interest Groups }}$}

Professional bodies and special interest groups within archaeology often publish guidelines and research frameworks for the study and archiving of artefacts as part of academic research and developer-driven projects (e.g. Brown 2007; PCRG 2010; Irving 2011). These documents, which are often freely available to download from the Web, are intended inform and encourage best practice. As such they represent an obvious place to seek clarification on the treatment of scientific samples post analysis. A survey of guidelines, mainly from the UK, where commercial archaeology is a well-established industry and numerous long-lived special interest pottery groups exist, reveal some pointers on what to do with preparations of ceramics after they have been studied. The so-called 'Standard for Pottery Studies in Archaeology', published jointly by Prehistoric Ceramics Research Group (PCRG), the Study Group for Roman Pottery (SGRP) and the Medieval Pottery Research Group (MPRG), advises that scientific specimens should be "included in the archive", along with the specimens from which they came (Barclay et al. 2016, p. 19). In cases where they are instead retained by the laboratory that analysed them, the guidelines suggest that their location be fully documented.

The recent 'Organic Residue Analysis and Archaeology Guidance for Good Practice' document and supporting information, that was published by Historic England (2017a, b), does not address the topic of the custody and treatment of lipid-extracted powders or other leftovers, post analysis. Despite being produced in consultation with "pottery specialists, museum curators, field archaeologists and local authority curators" (Historic England 2017a, p. ii), it only addresses the subject of digital archiving (Historic England 2017b, p. 21). Similar guidelines produced for the study pottery kiln sites (Historic England 2015, p. 29-30) focus solely on the future of the artefacts and data collected from them, despite strongly advocating thin section petrography, SEM-EDS and geochemistry as research tools in this area.

Guidelines on archiving archaeological finds have been published by bodies such as the Chartered Institute for Archaeologists (CIfA 2014), the Archaeological Archives Forum (AAF) (Brown 2007) and the European Archaeological Council (EAC) (Perrin et al. 2014). The former recommends that an archaeological archive should contain "all scientific samples suitable for curation, and associated documentation" (CIfA 2014, p. 10), though no specific reference is made to ceramics or particular types of samples prepared from them. The guidelines do not distinguish between archives kept at museums, academic collections or material stored at commercial units. However, the advice seems to be that they should remain with their parent artefacts and other materials from an excavation. The IFA advises somewhat ambiguously that when compiling archives containing scientific samples, project managers should "follow the archive standards of the relevant repository" and "liaise with specialists, laboratories and the archive repository over the archiving of scientific samples" (Brown 2007, p. 36, 39). On a more specific note, however, it recommends that access to appropriate equipment be available to examine the samples (Brown 2007, p. 37), which might be a useful criterion for deciding 
where specimens end up. The EAC 'STANDARD and GUIDE to BEST PRACTICE for ARCHAEOLOGICAL ARCHIVING in EUROPE' states that "generally, scientific samples should be treated as specified in the general guidelines above" (Perrin et al. 2014, p. 41) meaning that preparations be treated in the same manner as other items belonging to an archaeological archive. However, in cases where these are kept by a laboratory as reference material, the guide suggests that this be documented in the archive and "where possible a duplicate set of slides should accompany these records" (Perrin et al. 2014, p. 41). Thin sections are specifically mentioned in the document.

\section{$\underline{\text { Funding Agencies }}$}

National, regional and independent organisations that support archaeological research play an important role in the scientific analysis of ceramics by funding such activities. The decision whether to support a project or not is usually based on peer review of the academic merit, impact and feasibility of the proposed research. One aspect that is usually considered is the project's plan for the future of the outputs that it expects to produce. This includes the dissemination of research findings via presentation and publication, as well as the storage and accessibility of raw data. Major funding agencies, such as the National Science Foundation (NSF) in the USA and the National Environmental Research Council (NERC) in the UK publish guidelines for data management that applicants can consult when preparing a proposal. However, these do not normally provide guidance on the treatment of scientific samples post-analysis, archaeological or otherwise, despite these specimens often being included in their definitions of 'data'. The NSF's 'frequently asked questions' states that decisions about data management "will be determined by the community of interest through the process of peer review and program management" (NSF 2010), meaning that they are happy to pass the issue back to the archaeologists and analysts themselves. The Archaeological Data Service (ADS) is recommended as a data centre for the long-term curation of outputs produced by NERC funded research. However, the ADS covers digital data only and does not curate physical objects such as thin sections, polished blocks and the like.

In reviewing planned research and enabling it through financial support, funding agencies have the potential to encourage good practice in terms of the curation of and access to scientific preparations of ceramics and other artefacts. With this in mind it is surprising that such a loose approach prevails.

\section{Discussion and Recommendations}

The above discussion highlights the wide range of opinions, needs and practices that exist regarding the post-analysis treatment of scientific preparations of archaeological ceramics. Reconciling these is not any easy task and given that approaches vary between different laboratories, museums and analysts, a one-size-fits-all solution is unlikely to be appropriate. Individual projects, collaborations, commissions and requests for analysis of curated artefacts should instead be considered and negotiated on a case-by-case basis. Unfortunately, clear recommendations with which to do this are sorely lacking in the literature that exists on ceramic analysis, museum curation and collections management, archaeological law, as well as in most guidelines and best practice documents of specialist groups, professional bodies and funding agencies. In order to fill this gap, several key points are summarised below, which might be considered when deciding what to do with the scientific samples that are produced as a result of ceramic compositional analyses.

The question of whether scientific preparations of ancient pottery sherds or other ceramic objects are still artefacts is not easy to answer. As we have seen, it depends on the needs and perspective of the person making such a judgement. It is also related to the specific sample type in question and how close it resembles the parent artefact that it was produced from. The argument that intact mounted fragments such as SEM resin blocks and thin sections still constitute artefacts is clearly far stronger than that for highly transformed samples, such as INAA powders, XRF pellets and dissolved residues. 
The overall value of a particular analytical sample post analysis is strongly related to the likelihood of it being restudied. This varies depending its format and the apparatus needed to analyse it, with thin sections being the sample type most frequently reexamined for research and teaching purposes, followed by polished blocks and mounted SEM specimens. The other formats mentioned in this paper are rarely restudied, so it could be argued that their post-analysis research value is much lower. It is worth pointing out that the preparations with the greatest potential for further analysis, namely samples for optical and scanning electron microscopy, are those which are the least transformed and therefore bear most resemblance to their parent artefact. On the topic of value, it should be borne in mind that scientific preparations of ceramics can have additional worth, beyond their potential for reanalysis. This includes their role in telling the biography of the artefact that they were made from, as well as their value as an item for display in museums, or to demonstrate the research potential of a collection.

Where possible, scientific samples with high potential for re-analysis should reside in a location where the appropriate apparatus exists for their scientific study. For example, a petrographic microscope should be available for the consultation of thin sections. This will permit re-analysis and comparison with other material as part of future studies without the loan of material and its removal from its archive or laboratory slide collection.

As the re-analysis of scientific preparations of ceramics is the domain of analysts, a strong case can be made for them to retain custody of, or at least gain access to, those types of samples that are likely to be restudied. This is strongly juxtaposed with the role of curators and collections managers as custodians of archaeological artefacts, preserving them for future reference and maintaining an archive of associated material from their excavation and study. A case can also be made for archaeologists to retain the samples prepared and analysed as part of field projects, where these are likely to be restudied in the future. The needs of the other parties involved in the scientific analysis of ceramics, including commercial units, funding bodies and national ministries are arguably less important, though they may have a strong influence on the process. In order to reconcile differences of opinion regarding the future of scientific samples, open communication on this topic is key. This should take place as early as possible in order to avoid subsequent disputes about who owns the samples, where they should be housed and how they can be accessed.

When undertaking academic research projects that involve scientific ceramic analysis, a clear plan should preferably exist for the safe long-term storage and access to the specialist samples that will be produced. In the case of externally funded projects, the details of this should be included in any grant proposals. Funding bodies and their peer reviewers are encouraged to request such information in order to force analysts and principal investigators to consider the future of scientific sample collections resulting from their research and excavation, in addition to the data collected from them. Similar requirements might also be introduced by policy makers within archaeological law, though this should be done with detailed consideration of the needs of the main parties as well as the different sample types, rather than unilaterally.

In cases where analysts or archaeologists retain scientific samples prepared from ancient ceramics, their whereabouts should be documented in the archive in order to form a connection between an artefact and research conducted on it. This will hopefully prevent the unnecessary destruction of additional ceramic material from those artefacts that have already been sampled. Published studies that include ceramic analysis should state the whereabouts of and the procedures for accessing the scientific preparations that were made and analysed as part of the disseminated research. The acknowledgements section of journal articles, books or chapters is an appropriate location for the publication of this information (e.g. Ownby et al. 2016 and references therein; Cootes and Quinn 2017; Quinn et al. 2017). Where samples are returned to or remain with the museum or repository, the possibility for 
their loan or on-site study is essential in order for such specimens to have continued research potential and not just gather dust.

To summarise, a greater awareness of the issue of scientific sample value and custody is required within archaeological ceramic analysis., particularly the existence of different perspectives and needs. On a practical level an appropriate plan should be negotiated for the future of samples post-analysis, information on their whereabouts should be readily available and procedures for easy access and reanalysis should be put in place. This way these valuable specimens can hopefully be preserved and utilised for future research, whilst protecting the finite parent artefacts from which they were produced.

\section{Acknowledgements}

This article has benefitted from discussion with ceramic analysts, field archaeologists, curators, commercial units and funding agencies. These were approached individually via email. The author would like to thank all those who provided answers to his questions. Two anonymous reviewers also supplied useful feedback and ideas.

\section{References}

Albero Santacreu, D. 2014. Materiality, Techniques and Society in Pottery Production: The Technological Study of Archaeological Ceramics through Paste Analysis. De Gruyter Open, Warsaw, Poland.

Barclay, A. Knight, D., Booth, P., Evans, J., Brown, D. H. and Wood, I. 2016. A Standard for Pottery Studies in Archaeology. Pureprint, Uckfield, England.

Blake, J. 2015. International Cultural Heritage Law. Oxford University Press, Oxford.

British Museum (nd). SCIENTIFIC STUDY OF BRITISH MUSEUM COLLECTION MATERIAL: FORM EE1. Online document, British Museum.

(http://www.britishmuseum.org/about_us/departments/conservation_and_science/facili-

$\underline{\text { ties_and_services/collection_scientific_study.aspx }}$ )

Boulanger, M. T. and Stoner, W. D. 2013. Data Management and Sharing Plan. Online document, University of Missouri Research Reactor.

(http://archaeometry.missouri.edu/data_management_policy.html)

Brown, D. H. 2007. Archaeological Archives: A guide to best practice in creation, compilation, transfer and curation. Online document, Archaeological Archives Forum.

(http://www.archaeologists.net/sites/default/files/ifa_practice_archives.pdf)

Brown, D. H. 2003. A Review of Standards in England for the Creation, preparation and Deposition of Archaeological Archives. Online document, Archaeological Archives Forum.

(http://archives.archaeologyuk.org/Review_of_Archive_Standards.pdf)

CIfA. 2014. Standard and guidance for the creation, compilation, transfer and deposition of archaeological archive. Online document, Chartered Institute of Field Archaeologists. (http://www.archaeologists.net/sites/default/files/CIFAS\&GArchives_2.pdf)

Cordell, A. S., Wallis, N. J. and Kidder, G. 2017. Comparative Clay Analysis and Curation for Archaeological Pottery Studies. Advances in Archaeological Practice, 5: 93-106. 
Cootes, K. V. E. and Quinn, P. S. 2017. Prehistoric Settlement, Mobility and Societal Structure in the Peak District National Park: New Evidence from Ceramic Compositional Analysis. Archaeometry, DOI: $10.1111 /$ arcm.12334.

Fitz Gibbon, K. 2005. Who Owns the Past? Rutgers University Press, New Jersey.

Forrest, C. 2011. International Law and the Protection of Cultural Heritage. Routledge, London.

Fouque, F. 1879. Santorin et Ses Eruptions. The Johns Hopkins University Press, Baltimore.

Goren, Y. 2014. The operation of a portable petrographic thin-section laboratory for field samples. New York Microscopical Society Newsletter, September 2014: 1-17.

Hein, A. and Kilikoglou, V. 2012. ceraDAT: PROTOTYPE OF A WEB-BASED RELATIONAL DATABASE FOR ARCHAEOLOGICAL CERAMICS. Archaeometry 45: 1-17.

Henderson, J. 2000. The Science and Archaeology of Materials: An Investigation of Inorganic Materials. Routledge, London.

Historic England. 2017a. Organic Residue Analysis and Archaeology Guidance for Good Practice. Historic England, London.

Historic England. 2017b. Organic Residue Analysis and Archaeology Supporting Information. Historic England, London.

Historic England. 2015. Archaeological and Historic Pottery Production Sites: Guidelines for Best Practice. Historic England, London.

Hunt, A. (ed.) 2016. Oxford Handbook of Archaeological Ceramic Analysis. Oxford University Press. Ingham, J. P. 2010. Geomaterials Under the Microscope: A Colour Guide. Manson, London.

Irving, A. 2001. A Research Framework for Post-Roman Ceramic Studies in Britain. MEDIEVAL POTTERY RESEARCH GROUP OCCASIONAL PAPER NO. 6.

Keene, S. 2005. Fragments of the World: Uses of Museum Collections. Elsevier Butterworth-Heinemann, Oxford.

Lindeman, M. W. 2006. Archaeological Data Recovery for the Paseo de las Iglesias Project, Tucson, Pima County, Arizona. Technical Report No. 2013-01, Desert Archaeology, Inc., Tuscon, Arizona.

Lohman, J. 2009. Orbituary: Alan Vince. Archaeologist who transformed the study of Anglo-Saxon and medieval ceramics. The Guardian Newspaper. Wednesday 29 April 2009.

(https://www.theguardian.com/science/2009/apr/29/alan-vince-archaeologist-ceramics-obituary)

Matassa, F. 2011. Museum Collections Management: A handbook. Facet Publishing, London.

Morris, E. and Woodward, A. 2003. Ceramic Petrology and Prehistoric Pottery in the UK. Proceedings of the Prehistoric Society 69: 279-303. 
NSF, 2010. Data Management \& Sharing Frequently Asked Questions. Online document, National Science Foundation.

(https://www.nsf.gov/bfa/dias/policy/dmpfaqs.jsp\#1)

Orton, C. and Hughes, M. 2013 Pottery in Archaeology. Cambridge University Press.

Ownby, M. F., Druc, I. C. and Masucci, M. A. (eds.) 2016. Integrative Approaches in Ceramic Petrography. University of Utah Press, Salt Lake City.

Peabody Museum, 2016. Analytical Sampling Policies and Procedures. Online document, Peabody Museum for Archaeology and Anthropology at Harvard University.

(https://www.peabody.harvard.edu/files/Analytical\%20Sampling\%20Policies\%20and\%20Procedures_0.pdf)

Pearce, S. M. 1990. Archaeological Curatorship. Leicester Museum Studies.

Perrin, K., Brown, D. H., Lange, G., Bibby, D., Carlsson, A., Degraeve, A., Kuna, M., Larsson, Y., Palsdottir, S, U., Stoll-Tucker, B., Dunning, C. and Rogalla von Bieberstein, 2014. A STANDARD and GUIDE TO BEST PRACTICE FOR ARCHAEOLOGICAL ARCHIVING IN EUROPE. Europae Archaeologiae Consilium Guidelines 1. Namur, Belgium.

Peterson, S. E. 2001. Thin Section Petrography of Ceramic Cultural Materials. INSTAP Archaeological Excavation Manual 2, Institute for Aegean Prehistory Academic Press, Philadelphia.

Petrie, W. M. F. 1921. Corpus of Prehistoric Pottery and Palettes. British School of Archaeology in Egypt, London.

Pickard, R. 2016. Policy and Law in Heritage Conservation. Soon Press, London.

Pollard, A. M., Batt, C. M., Stern, B. and Young, S. M. M. 2007. Analytical Chemistry in Archaeology. Cambridge Manuals in Archaeology, Cambridge University Press.

Prehistoric Ceramics Research Group, 2010. The Study of Later Prehistoric Pottery: General Policies and Guidelines for analysis and Publications. 3rd Edition. Occasional Paper No1 and No 2. On-line document Prehistoric Ceramics Research Group.

(http://www.pcrg.org.uk/News_pages/PCRG\%20Gudielines\%203rd\%20Edition\%20(2010).pdf)

Prott, L. V. and O'Keef, P. J. 1988. Handbook of National Regulations Concerning the Export of Cultural Property. United Nations Educational, Scientific and Cultural Organization, Paris.

Quinn. P. S. 2017a. Petrographic Analysis of Prehistoric Ceramics from Whitemoor Haye, Staffordshire. Unpublished scientific report www.ceramicpetrology.co.uk. 2017/120.

Quinn. P. S. 2017b. Petrographic Analysis of Peterborough Ware Ceramics from West Amesbury Farm, Stonehenge, Wiltshire. Unpublished scientific report www.ceramicpetrology.co.uk. 2017/122.

Quinn, P. S. 2013. Ceramic Petrography: The Interpretation of Archaeological Pottery \& Related Artefacts in Thin Section. Archaeopress, Oxford.

Quinn, P. S., Zhang, S., Yin, X. and Li, X. 2017. Building the Terracotta Army: Ceramic Craft Technology and Organisation of Production at Qin Shihuang's Mausoleum Complex, China. Antiquity, 358. 
Quinn, P. S., Stringer, L., Rout, D., Alexander, T., Armstrong, A. and Olmstead, S. 2011. Petrodatabase: An On-line Database for Ceramic Petrography. Journal of Archaeological Science, 38: 24912496.

Reedy, C. L. 2008. Thin-Section Petrography of Stone \& Ceramic Materials. Archetype, London.

Rice, P. M. 1987. Pottery Analysis: A Sourcebook. University of Chicago Press.

Sullivan, L. P. and Childs, S. T. 2017. Managing Curated Collections: The Basics. in: Skeates, R. (ed.) Museums and Archaeology. Leicester Readers in Museum Studies: 57-62.

Tite, M. S. 1999. Pottery production, distribution, and consumption: The contribution of the physical sciences. Journal of Archaeological Method and Theory, 6: 181-233.

University of Wyoming Archaeological Repository. 2017. Guidelines and Standards. Online document, University of Wyoming.

(http://wyoarchaeo.state.wy.us/pdf/repository_guidelines.pdf)

Vince, A. 2005. Ceramic Petrology and the Study of Anglo-Saxon and Later Medieval Ceramics. Medieval Archaeology, 49: 219-245.

Worley, N. 1999. HENRY CLIFTON SORBY (1826-1908) and the DEVELOPMENT of THIN SECTION PETROGRAPHY in SHEFFIELD, in: Quinn, P. S. (ed.) INTERPRETING SILENT ARTEFACTS: Petrographic Approaches to Archaeological Ceramics. Archaeopress, Oxford: 1-9. 